\title{
Does Serum Zinc Level Affect Severity of Acute Gastroenteritis Among Pre-School Thai Children?
}

\section{Anundorn Wongteerasut Waewploy Pranweerapaibul}

Division of Gastroenterology and Hepatology, Department of Pediatrics, Phramongkutklao Hospital and Phramongkutklao College of Medicine, Bangkok, Thailand
Correspondence: Anundorn

Wongteerasut

Division of Gastroenterology and

Hepatology, Department of Pediatrics,

Phramongkutklao Hospital and

Phramongkutklao College of Medicine,

3 I5 Ratchawithi Road, Ratchathewi,

Bangkok, 10400, Thailand

Tel +66840022121

Fax +6627639300

Email anundorn@gmail.com
Introduction: Acute gastroenteritis (AGE) is a common problem causing significant mortality and morbidity among children. In clinical settings, zinc deficiency leads to diminished resistance to infectious disorders including acute gastroenteritis, especially in the pediatric populations.

Purpose: This study aimed to identify the possible effect of body zinc depletion on the severity of acute gastroenteritis among children. The parameters included dehydration status estimated by Modified Vesikari Score (MVS), laboratory findings, amount of intravenous (IV) fluid requirement, need of medications, as well as a clinical course of illness.

Materials and Methods: We conducted a prospective observational study with 107 children 3 months to 5 years old with AGE that were admitted to an inpatient unit. A comparison was made between children with normal $(\geq 80 \mu \mathrm{g} / \mathrm{dL}: \mathrm{n}=79$ cases $)$ and low serum zinc levels $(<80 \mu \mathrm{g} / \mathrm{dL}, \mathrm{n}=28$ cases $)$.

Results: The definite zinc deficiency $(<60 \mu \mathrm{g} / \mathrm{dL})$ was demonstrated only in $3.7 \%$ of cases. The severity of dehydration, classified by MVS, reveals a significantly higher increase in children with low serum zinc levels $(12.13 \pm 2.4$ vs $13.14 \pm 1.86$ points, $p<0.045)$. Additionally, the children with low serum zinc levels had a significantly higher number of prolonged vomiting episodes more than 24 hours $(42.4 \%$ vs $72 \%, p=0.013)$ and three cases of post-gastroenteritis complications, which are prolonged fever and persistent diarrhea, were identified only among patients with low zinc levels $(\mathrm{p}=0.003)$. However, there was no significant difference in IV fluid requirement, a need for medications, as well as the duration of hospitalization between the groups.

Conclusion: A significantly higher dehydration score, which was assessed by MVS, was demonstrated in the participants with low serum zinc levels. Furthermore, the number of children with prolonged vomiting as well as the evidence of post-gastroenteritis complications was also significantly higher in this group.

Keywords: serum zinc, acute gastroenteritis, Modified Vesikari Score, children

\section{Introduction}

Acute gastroenteritis (AGE) is a common problem in the pediatric age group causing significant mortality and morbidity to children together with a consequence of caregivers; moreover, this problem is the fifth leading cause of death for children worldwide. ${ }^{1}$ Prevalence also differs and is influenced by country, socio-economic status, parental education, habit and lifestyle. ${ }^{2-4}$ The common etiologies in childhood are viral pathogens, which are $75 \%$ to $80 \%$ of the cases and bacterial causes account for around $20 \%{ }^{1}$ Zinc is an essential micronutrient and requirement for physiological functions of humans, such as gene expression, protein synthesis, cell division, cellular metabolism, bone growth, intestinal fluid-electrolyte transport, the reproductive 
system, as well as important for immunological functions. ${ }^{5,6}$ Zinc has no long-term body storage or specific regulatory system; consequently, continuous daily zinc intake is important to maintain adequate zinc level. ${ }^{7,8}$ The long-term effects of zinc depletion among children presented problems of the immune system, gastrointestinal integrity, taste disorders, skin or hair problems, growth failure, male hypogonadism, sensorineural problems and also affected the healing process. ${ }^{9-11}$ Currently, the definition of serum zinc is defined by the Japanese Society of Clinical Nutrition with $<60 \mu \mathrm{g} / \mathrm{dL}$ as a significant deficiency, 60 to $<80 \mu \mathrm{g} / \mathrm{dL}$ as a marginal or subclinical deficiency as well as $\geq 80$ to $<130$ $\mu \mathrm{g} / \mathrm{dL}$ as a normal serum zinc level. ${ }^{11}$ Zinc deficiency is a common global problem, and around $20 \%$ of the worldwide population are at risk of inadequate zinc consumption. $^{12}$ Moreover, $1-3 \%$ of children in the US presented actual zinc deficiency status. ${ }^{8}$ This problem is especially prominent in developing countries. The status of zinc deficiency in South Asian countries was revealed by Akhtar S. demonstrating that zinc deficiency was highly prevalent among children, pregnant and lactating women. Furthermore, the prevalence of zinc deficiency among Indian children totaled around $40 \%{ }^{13}$ The status of this problem in two studies, by Udomkesmalee et al and Thurlow et al, was reported in the northeast region of Thailand. The prevalence of zinc deficiency was verified at $57 \%$ to $70 \%$ of these children 6 to 13 years old. ${ }^{14,15}$ WHO and UNICEF have recommended low-dose zinc supplementation in gastroenteritis as universal treatment. In addition, clinical studies have reported zinc supplementation reduced the duration and severity of diarrhea among young children, especially those in developing countries. $^{16,17}$

The severity of dehydration status, especially among children, may be correlated with history and physical examination. The degree of dehydration status can have an effect on hemogram parameters. Moreover, in clinical studies, the dehydration status score is one of the options to assess disease severity and hydration status. Few clinical dehydration scales to evaluate dehydration status were used previously. The Modified Vesikari Score (MVS) has been widely used and effective estimates in pediatric acute gastroenteritis settings. ${ }^{18,19}$ This score ranges from 0 to 20 and a higher number indicates a greater degree of dehydration.

This study aimed to identify the possible effect of body zinc depletion or deficiency on the severity of acute gastroenteritis among children. The outcome assessment of the dehydration status included MVS, the clinical course of children, laboratory investigation associated with dehydration, long-term complications and the duration of hospitalization. Furthermore, we aimed to identify the status of serum zinc levels among children residing in Bangkok, Thailand.

\section{Materials and Methods}

We introduced a prospective observational study that included children 3 months to 5 years old with acute gastroenteritis admitted to the inpatient unit of the Department of Pediatrics, Phramongkutklao Hospital, Bangkok, Thailand between January and October 2019. Acute gastroenteritis was defined as a loose or watery consistency of stool or an increased frequency of bowel movement ( $\geq 3$ daily), with or without fever or vomiting. The duration of diarrhea was not more than 14 days. $^{20}$ Patients with chronic diseases that may cause prolonged duration of gastroenteritis such as chronic gastrointestinal disorders, immune deficiency states, or intestinal malabsorption were omitted from enrollment.

\section{Data Collection}

The information from this study was later explained by investigators to parents or legal guardians. The informed consent was signed before enrollment and collection of the blood sampling. At the admission, five milliliters $(\mathrm{mL})$ of blood, stool and urinary sampling were collected to measure laboratory parameters, which are serum zinc level, complete blood count, serum electrolyte, blood urea nitrogen (BUN), serum creatinine $(\mathrm{Cr})$, urine examination and urine ketone. For zinc level, metal-free syringes and blood tubes were used to collect the blood sample. Blood samples were collected, centrifuged and stored at $-20^{\circ} \mathrm{C}$ until zinc level was measured. The measurement of zinc level was performed with inductively coupled plasma-mass spectroscopy (ICP-MS) with dynamic reaction cell technology (ELAN ${ }^{\circledR}$; Perkin Elmer, CT, USA). A stool sample was collected to identify gastrointestinal pathogenic bacteria using a conventional stool culture, which is selective and enrichment media. A stool testing with a chromatographic immunoassay for the qualitative detection of Rotavirus, Adenovirus and Norovirus was collected.

Additionally, we allocated children to two groups depending on serum zinc level. The first group had a normal serum zinc level, $\geq 80 \mu \mathrm{g} / \mathrm{dL}$, and the second group had a subclinical or significant zinc deficiency with serum zinc level $<80 \mu \mathrm{g} / \mathrm{dL}^{11}$ defined as the low serum zinc 
group. Further, we evaluated investigations representing a hydration status or gastroenteritis severities such as hematocrit level, white blood cell count, BUN, Cr, presence of hyponatremia (serum sodium $<135 \mathrm{mEq} / \mathrm{L}$ ) as well as hypokalemia (serum potassium $<3.5 \mathrm{mEq} / \mathrm{L}$ ), metabolic acidosis (serum bicarbonate $<17 \mathrm{mEq} / \mathrm{L}$ ), and urine specific gravity and positive of urine ketone. ${ }^{21-25}$ After that, the standard treatments for acute gastroenteritis were provided for all participants, including correcting fluid-electrolyte balance, specific medications such as antidiarrheal agents or antibiotics, supportive or symptomatic medication and re-evaluation of dehydration status. Repeated blood sampling was considered according to the clinical and course of the treatment.

\section{Primary Outcome}

The Modified Vesikari Score (MVS) was obtained to determine the severity of acute gastroenteritis. ${ }^{18-20}$ This score was finalized after the observational period. The follow-up details to calculated MVS were collected by scheduled healthcare visits and telephone following hospitalization within two weeks. This score ranged from 0 to 20. Moreover, dehydration status was classified in mild, moderate and severe levels as demonstrated in Table 1.

\section{Secondary Outcome}

The clinical course collected during the treatment and follow-up period included the duration of vomit and diarrhea episodes, the maximum number of vomit and bowel movements daily as well as the need for medical visits for the persistence of associated symptoms. Treatment parameters representing the severity and dehydration of gastroenteritis that were collected included the volume of intravenous (IV) fluid (rapid IV infusion constituted the isotonic crystalloid solution, normal saline or Ringer's lactate solution, prescribed in the first two hours of treatment to correct significant dehydration status and the total IV fluid required in first 24 hours of admission, including the volume of rapid IV infusion), needed for medication associated with diarrhea such as antibiotics, IV antiemetic agents, anti-diarrheal agents, as well as the duration of hospitalization.

Moreover, post-gastroenteritis complications, for example, chronic diarrhea, persistent abdominal pain, feeding problems, unscheduled medical visits and the need for re-admission were collected from both groups.

\section{Statistical Analysis}

Continuous data were compared between normal and low serum zinc-level groups using Student's $t$-test, whereas the categorical data used the chi-square and Fisher's exact tests. Mean \pm standard deviation (SD) was used to describe continuous data, which was normally distributed data using the Kolmogorov-Smirnov test. Statistical significance was accepted at p-value $<0.050$. Data were analyzed using the Statistical Package for Social Sciences (SPSS), Version 23.0 (IBM corp., Armonk, NY, USA). Sample size calculation was calculated from the data of Eskandar et $\mathrm{al}^{26}$ reporting a prevalence of zinc deficiency at 56\% of participants. The size was calculated with a power of $80 \%$ and level of significance at $5 \%$. The number of children including $10 \%$ of children lost to follow-up totaled 104 cases.

The ethics committee of Phramongkutklao Hospital and Phramongkutklao College of Medicine approved this study with protocol number $\mathrm{S} 042 \mathrm{~h} / 61$. Informed consent was confirmed by the committee following the principles of the Declaration of Helsinki 2000.

Table I The Details of the Modified Vesikari Score (MVS) That We Used to Identify the Dehydration Score in This Study ${ }^{18-20}$

\begin{tabular}{|c|c|c|c|c|}
\hline \multirow[t]{2}{*}{ Components } & \multicolumn{4}{|c|}{ Score on Vesikari Scale } \\
\hline & 0 Point & I Point & 2 Points & 3 Points \\
\hline Duration of diarrheal symptoms (hours) & 0 & $\mathrm{I}-96$ & $97-120$ & $\geq 120$ \\
\hline Maximum number of watery stools in 24 hours & 0 & $\mathrm{I}-3$ & $4-5$ & $\geq 6$ \\
\hline Duration of vomiting (hours) & 0 & $\mathrm{I}-24$ & $25-48$ & $\geq 49$ \\
\hline Maximum number of vomiting in 24 hours & 0 & I & $2-4$ & $\geq 5$ \\
\hline Maximum recorded fever, rectal $\left({ }^{\circ} \mathrm{C}\right)$ & $<37.0$ & $37.1-38.4$ & $38.5-38.9$ & $\geq 39.0$ \\
\hline Unscheduled health care visit & 0 & NA & Primary care & Emergency department \\
\hline Treatment & None & Rehydration with IV fluid & Hospitalization & NA \\
\hline
\end{tabular}

Abbreviations: ${ }^{\circ} \mathrm{C}$, degree Celsius; NA, not applicable; IV, intravenous. 


\section{Results}

The number of children enrolled in this cohort totaled 107 cases. Of these, $57 \%$ were male, mean body mass index (BMI) was $15.54 \pm 3.55 \mathrm{~kg} / \mathrm{m}^{2}$ and mean age was $29.36 \pm 19.65$ months. A common etiology of AGE was norovirus infection, comprising $18 \%$ of cases. However, Salmonella and rotavirus gastroenteritis were identified in $16 \%$ and $10 \%$, respectively. Fifty-three percent of patients could not identify the cause of diarrhea. Most participants $(75 \%)$ had a single medical visit before hospitalization. Fever was recorded in $75 \%$, vomiting and mucous bloody diarrhea were identified in $77.6 \%$ and $9.3 \%$, respectively. The mean number of daily bowel movements was $5.82 \pm 3.21$ and $4.44 \pm 2.73$ was the mean number of vomiting episodes before admission. The mean duration of diarrhea and vomiting episodes was $1.93 \pm 1.35$ days and $1.83 \pm 1.13$ days, respectively. Demographic profiles of the participants are demonstrated in Table 2.

Subsequently, the participants were categorized into two groups based on normal and low serum zinc levels, as shown in Table 3. The number of children with normal serum zinc levels totaled 79 cases (74\%) and 28 cases (26\%) were enrolled as low serum zinc status. Of these, a definite zinc level, below $<60 \mu \mathrm{g} / \mathrm{dL}$, was detected in only 4 cases $(3.7 \%)$ of this cohort. Mean serum zinc of both categories was identified at $117.29 \pm 25.72$ and 68.23 $\pm 7.68 \mu \mathrm{g} / \mathrm{dL}$, respectively. The demographics of children, clinical setting and dehydration status at the time of admission were compared and demonstrated no significant difference in mean age, BMI, birth weight and etiologies of gastroenteritis. However, the male gender was more prominent in normal serum zinc group, which is $64.6 \%$ vs $39.3 \%$ and $p$-value $=0.02$. For clinical causes, no statistical difference was demonstrated in the duration of diarrhea, stool characteristic, duration of vomiting episodes and the number of medical visits before being hospitalized between the two groups.

However, the dehydration status calculated from MVS revealed a statistical significance among children who had differences in serum zinc status $(12.13 \pm 2.4$ vs $13.14 \pm$ $1.86, \mathrm{p}<0.045)$. Moreover, a higher number of severe dehydration status (MVS $\geq 11$ ) were identified in the low serum zinc-level group ( $69.6 \%$ vs $89.3 \%)$ with $\mathrm{p}=0.040$. However, no significant difference was revealed in abnormal laboratory data affected by dehydration status and the severity of acute gastroenteritis between the groups.
Table 2 Demographic Data of Patients in This Study Enrolled at In-Patient of the Pediatric Department, Phramongkutklao Hospital, Bangkok, Thailand (January 2019 to October 2019)

\begin{tabular}{|c|c|}
\hline Demographic Profiles of Children & Results \\
\hline Total number of children, cases (\%) & 107 \\
\hline Etiology of acute gastroenteritis, cases (\%) & \\
\hline -Rotavirus & II (I0) \\
\hline -Norovirus & $19(18)$ \\
\hline -Adenovirus & $3(3)$ \\
\hline -Salmonella spp. & $17(16)$ \\
\hline -Unknown cause & $57(53)$ \\
\hline Male, cases (\%) & $62(57)$ \\
\hline Age (months), mean $\pm \mathrm{SD}$ & $29.36 \pm 19.65$ \\
\hline Birth weight (grams), mean $\pm S D$ & $2892.5 \pm 548.66$ \\
\hline BMI $\left(\mathrm{kg} / \mathrm{m}^{2}\right)$, mean $\pm \mathrm{SD}$ & $15.54 \pm 3.55$ \\
\hline $\begin{array}{l}\text { Number of medical visits before admission, mean } \\
\pm \text { SD }\end{array}$ & \\
\hline -Single, cases $(\%)$ & 81 (75.7) \\
\hline -Two, cases (\%) & $23(21.5)$ \\
\hline -Three, cases (\%) & $3(2.8)$ \\
\hline Fever, cases (\%) & 81 (75.7) \\
\hline First temperature $\left({ }^{\circ} \mathrm{C}\right)$, mean $\pm \mathrm{SD}$ & $37.44 \pm 0.91$ \\
\hline Mucous bloody diarrhea, cases (\%) & $10(9.30)$ \\
\hline Vomiting, cases (\%) & $83(77.6)$ \\
\hline Abdominal pain, cases (\%) & $7(6.5)$ \\
\hline $\begin{array}{l}\text { Duration of diarrhea before admission (days), } \\
\text { mean } \pm \text { SD }\end{array}$ & $1.93 \pm 1.35$ \\
\hline $\begin{array}{l}\text { Duration of vomiting before admission (days), } \\
\text { mean } \pm \text { SD }\end{array}$ & $1.83 \pm 1.13$ \\
\hline Number of bowel movement per day, mean \pm SD & $5.82 \pm 3.21$ \\
\hline Number of vomit per day, mean \pm SD & $4.44 \pm 2.73$ \\
\hline
\end{tabular}

Note: Data are presented as mean \pm SD for continuous variables and number (\%) for categorical variable.

Abbreviations: $\%$, percent; \pm , plus-minus; SD, standard deviation; BMI, body mass index; $\mathrm{kg} / \mathrm{m}^{2}$, kilogram per square meter; ${ }^{\circ} \mathrm{C}$, degree Celsius.

The clinical course of children is demonstrated in Table 4. From these data, participants with normal serum zinc levels required a slightly low volume of the rapid IV infusion than children with low zinc levels $(12.74 \pm 5.84 \mathrm{~mL} / \mathrm{kg}$ vs $13.86 \pm 5.18 \mathrm{~mL} / \mathrm{kg}, \mathrm{p}=0.422)$. This finding also showed in the total volume of the first 24 hours between groups $(123.56 \pm 22.09 \mathrm{~mL} / \mathrm{kg}$ vs $132.21 \pm 19.61 \mathrm{~mL} / \mathrm{kg}, \mathrm{p}=0.079)$. However, no significant difference was identified in IV fluid requirement 
Table 3 Comparison of Clinical, Investigation and the Dehydration Status of Patient Who Had Normal and Low Serum Zinc Level

\begin{tabular}{|c|c|c|c|}
\hline & $\begin{array}{l}\text { Normal Serum Zinc } 79 \text { Cases } \\
\text { (74\%) }\end{array}$ & $\begin{array}{l}\text { Low Serum Zinc } 28 \text { Cases } \\
\qquad(26 \%)\end{array}$ & p-value \\
\hline Serum zinc level $(\mu \mathrm{g} / \mathrm{dL})$, mean $\pm \mathrm{SD}$ & $117.29 \pm 25.72$ & $68.23 \pm 7.68$ & NA \\
\hline Male gender, cases (\%) & $51(64.6)$ & II (39.3) & $0.02 *$ \\
\hline Age (months), mean \pm SD & $24.66 \pm 19.07$ & $27.32 \pm 21.46$ & 0.54 \\
\hline BMI $\left(\mathrm{kg} / \mathrm{m}^{2}\right)$, mean $\pm \mathrm{SD}$ & $15.7 \mid \pm 3.19$ & $15.05 \pm 4.44$ & 0.397 \\
\hline Birth weight $(\mathrm{kg})$, mean \pm SD & $2914.14 \pm 547.34$ & $2831.43 \pm 557.79$ & 0.496 \\
\hline Cause of diarrhea: cases (\%) & & & 0.34 \\
\hline -Rotavirus & $9(11)$ & $2(7)$ & \\
\hline -Norovirus & II (14) & $8(29)$ & \\
\hline -Adenovirus & $3(4)$ & $0(0)$ & \\
\hline -Salmonella & II (14) & $6(21)$ & \\
\hline -Unknown & $45(57)$ & $12(43)$ & \\
\hline Number of visits before admission: cases (\%) & & & 0.824 \\
\hline -Single & $61(77.2)$ & $20(71.4)$ & \\
\hline- Two & $16(20.3)$ & $7(25)$ & \\
\hline -Three & $2(2.5)$ & I (3.6) & \\
\hline Duration of diarrhea (day), mean \pm SD & $1.92 \pm 1.38$ & $1.96 \pm 1.25$ & 0.903 \\
\hline Mucous bloody diarrhea, cases (\%) & $6(7.6)$ & $4(14.3)$ & 0.296 \\
\hline Duration of vomiting (day), mean $\pm S D$ & $1.73 \pm 1.06$ & $2.08 \pm 1.26$ & 0.194 \\
\hline Fever (cases) & $60(75.9)$ & $21(75)$ & 0.92 \\
\hline Abdominal pain (cases) & $3(3.8)$ & $4(14.3)$ & 0.054 \\
\hline Modified Vesikari Score (MVS) (0-20), mean \pm SD & $12.13 \pm 2.4$ & $13.14 \pm 1.86$ & $0.045^{*}$ \\
\hline Severe dehydration (MVS $\geq I I)$, cases (\%) & $55(69.6)$ & $25(89.3)$ & $0.040^{*}$ \\
\hline \multicolumn{4}{|l|}{ Investigations: } \\
\hline Hematocrit (\%) & $35.61 \pm 3.23$ & $34.16 \pm 3.76$ & 0.054 \\
\hline WBC (per cu.mm.), mean \pm SD & $15,888.8 \mid \pm 30,266.78$ & $10,253.57 \pm 3870.64$ & 0.33 \\
\hline Platelet (per cu.mm.), mean \pm SD & $384,645.57 \pm 144,830.05$ & $375,107.14 \pm 144,190.8$ & 0.765 \\
\hline BUN, mean \pm SD & $11.23 \pm 4.33$ & $12.02 \pm 5.65$ & 0.448 \\
\hline Creatinine, mean \pm SD & $0.28 \pm 0.08$ & $0.28 \pm 0.09$ & 0.873 \\
\hline BUN/Creatinine ratio, mean \pm SD & $41.7 \pm 19.48$ & $44.48 \pm 20.28$ & 0.524 \\
\hline Minimum serum sodium, mean $\pm S D$ & $137.53 \pm 2.46$ & $|37.9| \pm 2.75$ & 0.497 \\
\hline Hyponatremia ( $\mathrm{Na}<135$ mEq/L), case (\%) & $12(15.2)$ & $3(10.7)$ & 0.558 \\
\hline Minimum serum potassium $(\mathrm{mEq} / \mathrm{L})$, mean $\pm \mathrm{SD}$ & $3.94 \pm 0.48$ & $4.15 \pm 0.55$ & 0.058 \\
\hline Hypokalemia $(\mathrm{K}<3.5 \mathrm{mEq} / \mathrm{L})$, case $(\%)$ & $17(2 \mid .5)$ & $2(7.1)$ & 0.087 \\
\hline Minimum serum bicarbonate $(\mathrm{mEq} / \mathrm{L})$, mean $\pm \mathrm{SD}$ & $17.45 \pm 3.54$ & $16.3 \pm 3.35$ & 0.138 \\
\hline $\begin{array}{l}\text { Metabolic acidosis (serum bicarbonate }<17 \mathrm{mEq} / \mathrm{L} \text { ), } \\
\text { cases (\%) }\end{array}$ & $37(46.8)$ & $15(53.6)$ & 0.54 \\
\hline
\end{tabular}


Table 3 (Continued).

\begin{tabular}{|l|c|c|c|}
\hline & $\begin{array}{c}\text { Normal Serum Zinc 79 Cases } \\
\mathbf{( 7 4 \% )}\end{array}$ & $\begin{array}{c}\text { Low Serum Zinc 28 Cases } \\
\text { (26\%) }\end{array}$ & p-value \\
\hline Urine specific gravity, mean \pm SD & $1.014 \pm 9.77$ & $1.015 \pm 7.91$ & 0.694 \\
\hline Positive urine ketone, cases (\%) & $36(47.4)$ & $18(69.2)$ & 0.054 \\
\hline
\end{tabular}

Notes: Data are presented as mean \pm SD for continuous variables and number (\%) for categorical variable. *Significant at $p<0.050$

Abbreviations: ug/dL, microgram per deciliter; \pm , plus-minus; SD, standard deviation; NA, not applicable; \%, percent; BMI, body mass index; kg/m², kilogram per square meter; kg, kilogram; MVS, Modified Vesikari Score; WBC, white blood count; cu.mm., cubic milliliter; BUN, blood urea nitrogen; Na, sodium; K, potassium; mEq/L, milliequivalent per liter.

Table 4 Comparison of Treatment and Long-Term Clinical Course of Patients Who Had Normal and Low Serum Zinc Level

\begin{tabular}{|l|c|c|c|}
\hline & Normal Serum Zinc & Low Serum Zinc & p-value \\
\hline Need Rapid IV fluid infusion, cases (\%) & $62(78.5)$ & $23(85.2)$ & $0.45 \mathrm{I}$ \\
Rapid IV fluid infusion (mL/kg), mean \pm SD & $12.74 \pm 5.84$ & $13.86 \pm 5.18$ & 0.422 \\
IV fluid infusion (first 24 hour) (mL/kg), mean \pm SD & $113.44 \pm 19.74$ & $120.77 \pm 18.46$ & 0.099 \\
Total IV fluid infusion (first 24 hours) (mL/kg), mean \pm SD & $123.56 \pm 22.09$ & $132.21 \pm 19.61$ & 0.079 \\
Need IV antiemetic, cases (\%) & $5(6.3)$ & $1(3.6)$ & 0.648 \\
Need antibiotics, cases (\%) & $5(6.3)$ & $1(3.6)$ & 0.586 \\
Need anti-diarrheal agents, cases (\%) & $20(25.3)$ & $7(25)$ & 0.974 \\
Maximum temperature (degree Celsius), mean \pm SD & $38.17 \pm 1.04$ & $38.03 \pm 1.06$ & 0.535 \\
Maximum frequency of diarrhea (per day), mean \pm SD & $5.99 \pm 3.31$ & $5.36 \pm 2.95$ & 0.375 \\
Prolonged diarrhea > 96 hours, cases (\%) & $5(6.3)$ & $3(11.1)$ & 0.417 \\
Maximum frequency of vomit (per day), mean \pm SD & $4.27 \pm 2.69$ & $4.84 \pm 2.84$ & 0.386 \\
Prolonged vomiting >24 hours, cases (\%) & $25(42.4)$ & $18(72)$ & $0.013^{*}$ \\
Post AGE complications, cases (\%) & $0(0)$ & $3(10.7)$ & $0.003^{*}$ \\
Duration of hospitalization (days), mean \pm SD & $3.15 \pm 1.5$ & $2.97 \pm 1.36$ & 0.573 \\
\hline
\end{tabular}

Notes: Data are presented as mean \pm SD for continuous variables and number $(\%)$ for categorical variable. $*$ Significant at $p<0.050$.

Abbreviations: \%, percent; $\mathrm{mL} / \mathrm{kg}$, milliliter per kilogram; \pm , plus-minus; SD, standard deviation; IV, intravenous; AGE, acute gastroenteritis.

within the first 24 hours of hospitalization. Additionally, the children with low serum zinc levels had a significantly higher number of prolonged ( $>24$ hours) vomiting of $42.4 \%$ vs $72 \%, p=0.013$. However, the number of children with prolonged ( $>96$ hours) diarrhea was slightly higher in the low zinc level $(6.3 \%$ vs $11.1 \%, \mathrm{p}=0.417)$. No statistical significance was determined regarding the duration of hospitalization (3.15 \pm 1.50 vs $2.97 \pm 1.36$ days, $\mathrm{p}=0.573$ ) or requirement of AGE-related medications (antibiotics, IV antiemetics or anti-diarrheal agents; $25.3 \%$ vs $25 \%, \mathrm{p}=0.974$ ) among the participating children. From this cohort, three cases of post-gastroenteritis complications were identified only among patients with low zinc levels ( 0 case vs 3 cases, $\mathrm{p}=0.003$. The details of the complications involved a case that presented prolonged fever ( $>5$ days) and two cases of persistent diarrhea ( $>14$ days). Moreover, three of these children also needed an unscheduled medical visit without re-admission.

\section{Discussion}

From our study, the prevalence of zinc deficiency $(<60 \mu \mathrm{g} /$ $\mathrm{dL}$ ) was low in Bangkok, Thailand. The definite deficiency was demonstrated only in $3.7 \%$ (4 of 107 cases), which was compatible with the prevalence in the USA. ${ }^{8}$ There is a possible correlation with a low number of protein-energy malnutrition cases in this city compared with another part of Thailand ${ }^{27,28}$ and reassigned of this country from lowincome to middle-income countries in the previous two decades. $^{29,30}$ Finally, these improvements also affected serum zinc status among children.

The data also revealed a statistical significance between low serum zinc level $(<80 \mu \mathrm{g} / \mathrm{dL})$ with an increased degree of dehydration (classified by MVS), higher number of participants with severe dehydration (MVS $\geq 11$ ), prolonged vomiting ( $>24$ hours) and postgastroenteritis complications. Our findings were compatible with those of the study by Eskander et al, revealing a clinical study of the correlation between serum zinc level 
and Vesikari Score among Egyptian children with acute gastroenteritis. This publication demonstrated a significant negative correlation of serum zinc level, dehydration score and duration of hospitalization $(\mathrm{p}<0.05) .{ }^{26}$ However, we could not identify the significance of the duration of hospitalization between normal and low serum zinc levels in our study. Our finding was also compatible with the report of Agarwal et al in India in which no relation was found in the duration of diarrhea with serum zinc level among 254 children, whereas children with biochemical zinc deficiency were more likely to be dehydrated and hospitalized. ${ }^{31}$

A benefit was observed of encouraging a high zinc intake in some regions that exhibited data on low daily zinc diets, such as African and South Asian together with Southeast Asian regions. ${ }^{12,32}$ Natural sources of zinc in food include lean meats, seafood, shellfish, legumes or seeds, dairy products and beans. Additionally, zinc concentration in breastfed infants is adequate for daily requirements until 6 months of life. After that, complimentary food is supplemented to maintain adequate body zinc concentration. ${ }^{33}$ Zinc supplementation among children with a high risk for deficiency decreased the morbidity in gastrointestinal and lower respiratory tract infections, decreased overall mortality, and improved weight and height among infants and young children. ${ }^{34,35}$ Moreover, various data about zinc supplementation indicated reduced severity and duration of diarrhea among children ${ }^{36-38}$ and also exhibited a positive effect to shorten the diarrheal duration in a clinical trial in Thailand. ${ }^{39}$ Therefore, 10 $20 \mathrm{mg}$ daily oral zinc supplementation, for 7-14 days, among children with acute gastroenteritis was also recommended from common pediatric clinical practice guidelines and recommendations, particularly in high-risk regions. ${ }^{20,40}$

This study confirmed that increased awareness in treating gastroenteritis and restoring adequate hydration among children presents a risk of developing zinc deficiency such as protein-energy malnutrition, preterm infants, and children with feeding problems.

In addition, serum zinc level will be an initial investigation and consider as a standard parameter for prediction of the clinical course including a dehydration status for childhood acute gastroenteritis in the future. In addition, zinc level is also an important parameter for consideration of zinc supplementation within gastroenteritis episodes. In spite of this, the low incidence of definite zinc deficiency $(<60 \mu \mathrm{g} / \mathrm{dL})$ was demonstrated in this study. There is significant evidence of a higher dehydration score in acute gastroenteritis children with low serum zinc levels $(<80 \mu \mathrm{g} / \mathrm{dL})$ when comparing with children who had a normal zinc status. Supplementation may have an effect on dehydration status and clinical manifestation. This issue needs further study for the advantage of the zinc supplementation among children who present with subclinical deficiency.

\section{Strength and Limitation}

This study included hospitalized children, so we could closely observe the clinical manifestation, requirement for treatment and also intensive observation of the clinical and dehydration status to estimate the dehydration score. Concerning the limitations of this study, we did not include the group of acute gastroenteritis in the outpatient unit that may have produced a different result. Also, these data represented the demographics and consequences of low serum zinc levels among children residing in Bangkok, Thailand, which has an extremely low incidence of definite zinc deficiency. Further, Bangkok provides a difference in availability of medical units and offers a higher number of health providers than other parts of the country.

\section{Conclusion}

A significantly higher dehydration score, which was assessed by MVS, was demonstrated among the participants with low serum zinc levels. In addition, the number of children with prolonged vomiting ( $>24$ hours), as well as the evidence of post-gastroenteritis complications, was also significantly higher in this group. However, the duration of diarrhea, hospitalization and requirement for therapy did not differ significantly between the groups.

\section{Acknowledgments}

The authors thank all members of the Department of Pediatrics, Phramongkutklao Hospital and also thank Phramongkutklao College of Medicine for funding support of this study. Dr. Nopaorn Phavichitr at the Department of Pediatrics, Phramongkutklao Hospital for her assistance.

\section{Author Contributions}

All authors made substantial contributions to conception and design, acquisition of data, or analysis and interpretation of data; took part in drafting the article or revising it critically for important intellectual content; agreed to submit to the current journal; gave final approval for the 
version to be published; and agreed to be accountable for all aspects of the work.

\section{Disclosure}

No potential conflict of interest was informed by the authors.

\section{References}

1. Hartman S, Brown E, Loomis E, Russell HA. Gastroenteritis in children. Am Fam Physician. 2019;99(3):159-165.

2. Elliott EJ. Acute gastroenteritis in children. BMJ. 2007;334 (7583):35-40. doi:10.1136/bmj.39036.406169.80

3. Thongprachum A, Khamrin P, Maneekarn N, Hayakawa S, Ushijima H. Epidemiology of gastroenteritis viruses in Japan: prevalence, seasonality, and outbreak. J Med Virol. 2016;88(4):551-570. doi: $10.1002 / j m v .24387$

4. Gosselin V, Petit G, Gagneur A, Genereux M. Trends in severe gastroenteritis among young children according to socio-economic characteristics before and after implementation of a rotavirus vaccination program in Quebec. Can J Public Health. 2016;107(2):e161e167. doi:10.17269/cjph.107.5286

5. Roy SK, Tomkins AM, Haider R, et al. Impact of zinc supplementation on subsequent growth and morbidity in Bangladeshi children with acute diarrhoea. Eur J Clin Nutr. 1999;53(7):529-534. doi:10. 1038/sj.ejcn.1600734

6. Prasad AS. Zinc in human health: effect of zinc on immune cells. Mol Med. 2008;14(5-6):353-357. doi:10.2119/2008-00033.Prasad

7. Bailey RL, West KP Jr, Black RE. The epidemiology of global micronutrient deficiencies. Ann Nutr Metab. 2015;66(Supp1 2):22-33. doi:10.1159/000371618

8. Corbo MD, Lam J. Zinc deficiency and its management in the pediatric population: a literature review and proposed etiologic classification. J Am Acad Dermatol. 2013;69(4):616-624 e1. doi:10.1016/j.jaad.2013.04.028

9. Nishi Y. Zinc and growth. $J$ Am Coll Nutr. 1996;15(4):340-344. doi:10.1080/07315724.1996.10718608

10. Prasad AS. Zinc in growth and development and spectrum of human zinc deficiency. $J$ Am Coll Nutr. 1988;7(5):377-384. doi:10.1080/ 07315724.1988.10720255

11. Nishikawa H, Enomoto H, Yoh K, et al. Serum zinc level classification system: usefulness in patients with liver cirrhosis. $J$ Clin Med. 2019;8(12):2057. doi:10.3390/jcm8122057

12. Wuehler SE, Peerson JM, Brown KH. Use of national food balance data to estimate the adequacy of zinc in national food supplies: methodology and regional estimates. Public Health Nutr. 2005;8 (7):812-819. doi:10.1079/phn2005724

13. Akhtar S. Zinc status in South Asian populations-an update. $J$ Health Popul Nutr. 2013;31(2):139-149. doi:10.3329/jhpn.v31i2.16378

14. Thurlow RA, Winichagoon P, Pongcharoen T, et al. Risk of zinc, iodine and other micronutrient deficiencies among school children in North East Thailand. Eur J Clin Nutr. 2006;60(5):623-632. doi:10. 1038/sj.ejcn.1602361

15. Udomkesmalee E, Dhanamitta S, Yhoung-Aree J, Rojroongwasinkul N, Smith JC Jr. Biochemical evidence suggestive of suboptimal zinc and vitamin A status in schoolchildren in northeast Thailand. Am J Clin Nutr. 1990;52(3):564-567. doi:10.1093/ ajcn/52.3.546

16. Lazzerini M, Ronfani L. Oral zinc for treating diarrhoea in children. Cochrane Database Syst Rev. 2008;3:CD005436. doi:10.1002/ 14651858.CD005436.pub2

17. Patro B, Golicki D, Szajewska H. Meta-analysis: zinc supplementation for acute gastroenteritis in children. Aliment Pharmacol Ther. 2008;28(6):713-723. doi:10.1111/j.1365-2036.2008.03787.x
18. Freedman SB, Eltorky M, Gorelick M; Pediatric Emergency Research Canada Gastroenteritis Study G. Evaluation of a gastroenteritis severity score for use in outpatient settings. Pediatrics. 2010;125(6):e1278-e1285. doi:10.1542/peds.2009-3270

19. Schnadower D, Tarr PI, Gorelick MH, et al. Validation of the modified vesikari score in children with gastroenteritis in 5 US emergency departments. J Pediatr Gastroenterol Nutr. 2013;57(4):514-519. doi:10.1097/MPG.0b013e31829ae5a3

20. Guarino A, Ashkenazi S, Gendrel D, et al. European society for pediatric gastroenterology, hepatology, and nutrition/European society for pediatric infectious diseases evidence-based guidelines for the management of acute gastroenteritis in children in Europe: update 2014. J Pediatr Gastroenterol Nutr. 2014;59(1):132-152. doi:10.1097/MPG.0000000000000375

21. Hall JE, Huynh PP, Mody AP, Wang VJ. Clinical utility of noninvasive method to measure specific gravity in the pediatric population. $J$ Emerg Med. 2018;54(4):440-446. doi:10.1016/j.jemermed.20 17.11.022

22. Hoxha TF, Azemi M, Avdiu M, Ismaili-Jaha V, Grajqevci V, Petrela E. The usefulness of clinical and laboratory parameters for predicting severity of dehydration in children with acute gastroenteritis. Med Arch. 2014;68(5):304-307. doi:10.5455/ medarh.2014.68.304-307

23. Shaoul R, Okev N, Tamir A, Lanir A, Jaffe M. Value of laboratory studies in assessment of dehydration in children. Ann Clin Biochem. 2004;41(Pt 3):192-196. doi:10.1258/000456304323019541

24. Baron S, Courbebaisse M, Lepicard EM, Friedlander G. Assessment of hydration status in a large population. Br J Nutr. 2015;113 (1):147-158. doi:10.1017/S0007114514003213

25. Tam RK, Wong H, Plint A, Lepage N, Filler G. Comparison of clinical and biochemical markers of dehydration with the clinical dehydration scale in children: a case comparison trial. $B M C$ Pediatr. 2014;14(1):149. doi:10.1186/1471-2431-14-149

26. Eskander AE, Sherif LS, Nabih M, et al. Serum zinc level and its correlation with vesikari system scoring in acute pediatric diarrhea. Open Access Maced J Med Sci. 2017;5(5):677-680. doi:10.3889/ oamjms.2017.097

27. Tontisirin K, Valyasevi A. Protein energy malnutrition related to diarrhea in Thai children. J Nutr Sci Vitaminol. 1981;27 (6):513-520. doi:10.3177/jnsv.27.513

28. Migasena P, Choopanya K. Nutrition and the environmental situation in Bangkok. Southeast Asian J Trop Med Public Health. 1992;23 (Suppl 3):46-53.

29. Winichagoon P. Thailand nutrition in transition: situation and challenges of maternal and child nutrition. Asia Pac J Clin Nutr. 2013;22 (1):6-15. doi:10.6133/apjen.2013.22.1.17

30. Tontisirin K, Kachondham Y, Winichagoon P. Trends in the development of Thailand's nutrition and health plans and programs. Asia Pac J Clin Nutr. 1992;1(4):231-238.

31. Agarwal A, Gupta NK, Upadhyay A, Soni RK, Shah D, Jaiswal V. Serum zinc levels as a predictor of severity of acute diarrhea. Indian J Pediatr. 2018;85(3):179-183. doi:10.1007/s12098-0172493-z

32. Wessells KR, Brown KH, Bhutta ZA. Estimating the global prevalence of zinc deficiency: results based on zinc availability in national food supplies and the prevalence of stunting. PLoS One. 2012;7(11): e50568. doi:10.1371/journal.pone. 0050568

33. Ackland ML, Michalczyk AA. Zinc and infant nutrition. Arch Biochem Biophys. 2016;611:51-57. doi:10.1016/j.abb.2016.06.011

34. Brown KH, Peerson JM, Baker SK, Hess SY. Preventive zinc supplementation among infants, preschoolers, and older prepubertal children. Food Nutr Bull. 2009;30(1 Suppl):S12-S40. doi:10.1177/ $15648265090301 \mathrm{~S} 103$

35. Donangelo CM, King JC. Maternal zinc intakes and homeostatic adjustments during pregnancy and lactation. Nutrients. 2012;4 (7):782-798. doi:10.3390/nu4070782 
36. Haider BA, Bhutta ZA. The effect of therapeutic zinc supplementation among young children with selected infections: a review of the evidence. Food Nutr Bull. 2009;30(1 Supp1):S41-S59. doi:10.1177/ $15648265090301 \mathrm{~S} 104$

37. Lazzerini M, Wanzira H. Oral zinc for treating diarrhoea in children. Cochrane Database Syst Rev. 2016;12:CD005436. doi:10.1002/146 51858.CD005436.pub5

38. El C, Celikkaya ME. Evaluation of the effects of zinc supplementation on the symptoms and duration of the disease in acute viral gastroenteritis. Fam Pract Palliat Care. 2019;4(1):11-14. doi:10.22 391/fppc. 471460
39. Rerksuppaphol L, Rerksuppaphol S. Efficacy of zinc supplementation in the management of acute diarrhoea: a randomised controlled trial. Paediatr Int Child Health. 2020;40(2):105-110. doi:10.1080/2046 9047.2019.1673548

40. Lo Vecchio A, Dias JA, Berkley JA, et al. Comparison of recommendations in clinical practice guidelines for acute gastroenteritis in children. J Pediatr Gastroenterol Nutr. 2016;63(2):226-235. doi:10. 1097/MPG.0000000000001133

\section{Publish your work in this journal}

Pediatric Health, Medicine and Therapeutics is an international, peerreviewed, open access journal publishing original research, reports, editorials, reviews and commentaries. All aspects of health maintenance, preventative measures and disease treatment interventions are addressed within the journal. Practitioners from all disciplines are invited to submit their work as well as healthcare researchers and patient support groups. The manuscript management system is completely online and includes a very quick and fair peer-review system. Visit http://www.dovepress.com/testimonials.php to read real quotes from published authors. 